\title{
Overcoming the transcatheter aortic valve replacement Achilles heel: paravalvular leak
}

\author{
Basel Ramlawi ${ }^{1}$, Kareem Bedeir ${ }^{2}$ \\ ${ }^{1}$ Cardiothoracic Surgery, Lankenau Heart Institute, Philadelphia, PA, USA; ${ }^{2}$ Cardiac Surgery, Brigham and Women's Hospital, Boston, MA, USA \\ Correspondence to: Basel Ramlawi, MD. Cardiothoracic Surgery, Lankenau Heart Institute, Philadelphia, PA, 19096 USA. \\ Email: Basel.Ramlawi@gmail.com.
}

Submitted May 31, 2020. Accepted for publication Jun 12, 2020.

doi: $10.21037 /$ acs-2020-av-19

View this article at: http://dx.doi.org/10.21037/acs-2020-av-19

Paravalvular leaks (PVLs) have been a major critique against transcatheter aortic valve replacement (TAVR) since its inception. Substantial research has been produced over the past decade, aiming to understand PVLs in terms of causes, predictors, impact on outcomes and potential solutions.

\section{Impact of PVL on clinical outcomes}

PVLs are not benign. Moderate-to-severe PVL after TAVR has been associated with a 3 -fold increase in early mortality, and a 2.3 -fold increase in mortality at 1 year (1). This correlation has been reproduced by most meta-analyses and registries regarding moderate and severe PVLs, although data regarding mild PVLs is conflicting (2-5). A plausible theory suggests that patients with baseline pure stenosis without insufficiency are less likely to tolerate PVL, even if mild, due to smaller and stiffer ventricles. Large leaks may lead to heart failure, while smaller leaks predispose to endocarditis or hemolysis, with the latter conferring poor prognosis, even if insufficient to cause significant anemia. Moreover, even mild PVL following TAVR was associated with increased all-cause mortality, compared to no/trace PVL (3).

\section{Imaging for PVL}

Given such impact on outcomes, accurate assessment of PVL is necessary. The jet should be analyzed in terms of number, location, direction, course and quantification. Unfortunately, PVLs are often multiple, eccentric and serpiginous, which makes quantification very challenging. Three-dimensional TEE has been shown to be superior to both TTE and two-dimensional TEE. Limitations related to acoustic shadowing can be mitigated by using multiple windows and combining TTE and TEE. Nonetheless, echocardiography lacks consensus in PVL quantification, partly related to prevalence of multiple jets, garden-hosing, and jet eccentricity. Angiographic contrast jet visualization and grading after transcatheter heart valve (THV) deployment is difficult to standardize. A useful and reliable angiographic tool is the aortic regurgitation index (ARI) the ratio of difference between aortic and ventricular pressures in end-diastole, and systolic blood pressure. This has been validated with index $<25$ correlating to severe PVL and predicting 1-year mortality (6). After TAVR, cardiac magnetic resonance (CMR) has emerged as an excellent tool for PVL assessment, especially with multiple jets. Using phase contrast velocity mapping, total PVL can be quantified accurately, although arrhythmias can be a limitation. This has been shown to be superior to and more reproducible than echocardiography. Cardiac computerized tomography (CT) has not been shown to have benefit over echocardiography in PVL assessment. With the above, it should be emphasized that the key to accurate PVL assessment is multi-modality imaging.

\section{Reduction in TAVR-related PVL}

A significant impact on mortality together with challenges in accurate assessment led to PVLs being regarded as TAVR's Achilles heel. More recent data however, suggests this perception may be outdated. Within the pivotal randomized trials in the United States, there were moderate-to-severe PVLs at 30 days in $9 \%$ of patients reported in 2014, but only $3 \%$ reported in 2019 , both 
using self-expanding valves. For balloon-expandable valves, moderate-to-severe PVLs at 30 days had $12 \%$ reported in 2011, while $<1 \%$ reported in 2019 (7-10). This multiplefold decrease in PVL rates over less than a decade is a multifactorial success. Valve designers have addressed PVLs with newer valve versions supplemented with an exterior inflow skirt that enhances left ventricular outflow tract (LVOT) apposition. An increased understanding of PVLs in terms of risk factors and management has also affected decisions related to choice of technique and prosthesis.

\section{Risk factors for PVL}

The ability to predict PVLs should lead to prevention and better management. This includes a "big picture" assessment of the patients' overall status, to what extent PVL is tolerated and whether surgical aortic valve replacement (SAVR) may be an option to avoid PVL altogether. Several factors increase risk of PVL following TAVR:

* Under-sizing and/or suboptimal TAVR prosthesis positioning.

* Steeper aorta-to-LVOT angle may lead to shallow THV implantation in relation to the non-coronary cusp.

* Significant calcifications of leaflets, annulus or LVOT, especially when bulky or asymmetric.

* Prominent ellipticity of the AV annulus.

* Males, New York Heart Association class IV and a native aortic valve.

* The use of older-generation TAVR.

In the great majority of cases, moderate-to-severe PVL should not be tolerated, and if this were difficult to avoid using TAVR, SAVR should be undertaken. The choice of THV should be tailored to the patient's anatomic characteristics, including the risk of PVL. In instances whereby PVL is predicted, some advocate pre-dilation, although its value in reducing PVL is questionable, and the risks related to rapid pacing and stroke may be significant. The use of newer-generation valves with incorporated "outer sealing skirt" reduces PVL rates (e.g., Evolut Pro, Lotus Edge, Sapien 3). Oversizing the THV by $1 \mathrm{~mm}$ or $10 \%$ of annular area as measured by CT has been shown to reduce moderate-to-severe PVLs. Retrievable THV allow for optimal positioning and should decrease malpositionrelated PVLs or coronary complications.

\section{Addressing PVL and technological advances}

Intraoperatively, multimodality imaging should be used, and persistence should be practiced with PVL detection and jet analysis. If uncertain, ARI should be calculated (DBP - LVEDP)/SBP. Leaks can be addressed by repeat postTAVR balloon dilation if incomplete expansion is suspected. Aggressive dilation, however, can result in catastrophic root rupture, and should be performed with caution. A malposition-related PVL can be addressed by deploying a valve-in-valve, with a properly positioned second valve. If a significant single and large PVL persists, transcatheter closure devices may be considered. Although none of these devices has been approved for this specific indication, they have been used with promising success. The Amplatz vascular plug (St. Jude Medical, St Paul, MN) is the most commonly used in the United States and is recapturable after deployment. In a meta-analysis of transcatheter PVL closure after SAVR's, the procedure was successful in $84 \%$ of patients and there was improvement in functional status or anemia in $71 \%(11)$.

The perception that moderate-to-severe PVL is the Achilles heel of TAVR may no longer be accurate. Presently, moderate-to-severe PVL is better understood, anticipated and managed, which has resulted in rates not significantly different to that of SAVR (7). The question remains of the real impact of mild PVLs on long-term outcomes, especially with the approval of TAVR in low-risk patients. Mild PVLs continue to be higher in TAVR, as compared to SAVR. In a young healthy patient with many decades ahead to live, a mild PVL will likely not be acceptable.

\section{Acknowledgments}

Funding: None.

\section{Footnote}

Conflicts of Interest: BR is a consultant for Liva Nova, Medtronic and Atricure. The other author has no conflicts of interest to declare.

Open Access Statement: This is an Open Access article distributed in accordance with the Creative Commons Attribution-NonCommercial-NoDerivs 4.0 International License (CC BY-NC-ND 4.0), which permits the noncommercial replication and distribution of the article with the strict proviso that no changes or edits are made and the original work is properly cited (including links to both the formal publication through the relevant DOI and the license). See: https://creativecommons.org/licenses/by-nc-nd/4.0/. 


\section{References}

1. Athappan G, Patvardhan E, Tuzcu EM, et al. Incidence, predictors, and outcomes of aortic regurgitation after transcatheter aortic valve replacement: meta-analysis and systematic review of literature. J Am Coll Cardiol 2013;61:1585-95.

2. Van Belle E, Juthier F, Susen S, et al. Postprocedural aortic regurgitation in balloon-expandable and selfexpandable transcatheter aortic valve replacement procedures: analysis of predictors and impact on longterm mortality: insights from the FRANCE2 Registry. Circulation 2014;129:1415-27.

3. Kodali SK, Williams MR, Smith CR, et al. Two-year outcomes after transcatheter or surgical aortic-valve replacement. N Engl J Med 2012;366:1686-95.

4. Gilard M, Eltchaninoff H, Iung B, et al. Registry of transcatheter aortic-valve implantation in high-risk patients. N Engl J Med 2012;366:1705-15.

5. Mack MJ, Leon MB, Smith CR, et al. 5-year outcomes of transcatheter aortic valve replacement or surgical aortic valve replacement for high surgical risk patients with aortic stenosis (PARTNER 1): a randomised controlled trial. Lancet 2015;385:2477-84.

6. Sinning JM, Vasa-Nicotera M, Chin D, et al. Evaluation and management of paravalvular aortic regurgitation after transcatheter aortic valve replacement. J Am Coll Cardiol 2013;62:11-20.

7. Mack MJ, Leon MB, Thourani VH, et al. Transcatheter Aortic-Valve Replacement with a Balloon-Expandable Valve in Low-Risk Patients. N Engl J Med 2019;380:1695-705.

8. Adams DH, Popma JJ, Reardon MJ. Transcatheter aorticvalve replacement with a self-expanding prosthesis. $\mathrm{N}$ Engl J Med 2014;371:967-8.

9. Popma JJ, Deeb GM, Yakubov SJ, et al. Transcatheter Aortic-Valve Replacement with a Self-Expanding Valve in Low-Risk Patients. N Engl J Med 2019;380:1706-15.

10. Smith CR, Leon MB, Mack MJ, et al. Transcatheter versus surgical aortic-valve replacement in high-risk patients. $\mathrm{N}$ Engl J Med 2011;364:2187-98.

11. Millan X, Skaf S, Joseph L, et al. Transcatheter reduction of paravalvular leaks: a systematic review and metaanalysis. Can J Cardiol 2015;31:260-9.
Cite this article as: Ramlawi B, Bedeir K. Overcoming the transcatheter aortic valve replacement Achilles heel: paravalvular leak. Ann Cardiothorac Surg 2020;9(6):499-501. doi: 10.21037/acs-2020-av-19 